\title{
ESTUDO PARA OTIMIZAÇÃO DA EXTRAÇÃO DE COMPOSTOS BIOATIVOS DA FOLHA DE GRAVIOLA (Annona muricata L.)
}

\author{
Júlia A. de L. Pereira (IC), Gustavo L. da Silva(IC), Ingrid V. M. de Moraes (PG), Flávio L. Schmidt (PQ)
}

\section{Resumo}

A folha da graviola é conhecida por ser rica em compostos bioativos. Esses compostos possuem grande atividade antioxidante que podem prevenir o surgimento e/ou o progresso de patologias oxidativas além de poder reduzir o risco de doenças, como o câncer, artrite, diabetes e outras doenças causadas pelo envelhecimento. Atualmente, a extração desses compostos tem se tornado objetivo de muitos estudos com o emprego de técnicas modernas de extração de modo a preservar compostos biotivos presentes em matrizes vegetais. Assim, este projeto se propôs a realizar um estudo visando a otimização da extração dos compostos bioativos da folha de graviola empregando a técnica de Screening Design e posteriormente realização de delineamento composto rotacional central (DCCR).

Palavras Chave: Extração, Graviola, Ultrassom.

\section{Introdução}

Muitos componentes bioativos têm sido encontrados na graviola, assim como cientistas têm estudado suas propriedades há alguns anos. Empresas brasileiras e de outros países têm comercializado a folha de graviola desidratada na forma de cápsulas e chás, contudo a tecnologia empregada na obtenção dos produtos é a simples secagem da folha seguida de trituração para obtenção do pó. Dessa forma, nos produtos atualmente comercializados os compostos bioativos presentes nas folhas encontram-se misturados a diversos outros compostos e suas concentrações na maioria das vezes não é determinada. Dentro do exposto o objetivo desse trabalho foi avaliar diferentes condições de extração dos compostos fenólicos de extratos obtidos a partir da folha de graviola, utilizando como variáveis de estudo a concentração de etanol (10 a 90\%), proporção de solvente/folha em pó $(10 \mathrm{~mL} / \mathrm{g}$ a $40 \mathrm{~mL} / \mathrm{g}$ ), temperatura (30 a $70^{\circ} \mathrm{C}$ ), potência de ultrassom (0 a 800 Watts), empregando o planejamento fracionado $2^{4-1}$ para a seleção de variáveis e suas faixas de utilização para posterior realização de delineamento composto rotacional central (DCCR). As variáveis resposta foram concentração de fenólicos totais ${ }^{1}$ e capacidade antioxidante ${ }^{2}$ pelo captura do radical livre ABTS +. . Para cada ensaio foi realizada uma cinética de extração nos tempos 0 , $5,15,30,45$ e 60 minutos. Os dados foram submetidos à ANOVA, utilizando o programa Statistica ${ }^{\circledR}$. O planejamento fracionado foi avaliado pela Tabela de Efeitos e gráfico de Pareto e as médias dos dados de cinética extração foram submetidas ao teste de Tukey $(p<0,05)$.
$\mathrm{Na}$ análise estatística do planejamento fracionado observou-se que nenhuma das variáveis avaliadas afetou significativamente a capacidade antioxidante dos extratos pelo método de quantificação utilizado, em todos os tempos de extração avaliados. Já as variáveis temperatura e concentração de solvente tiveram influência significativa na extração de fenólicos totais até o tempo de 15 minutos de extração. $O$ aumento da temperatura favoreceu $\mathrm{o}$ aumento da concentração de fenólicos e o aumento da proporção de solvente/folha prejudicou a extração de fenólicos. A partir dos 45 minutos de extração - aumento da concentração de etanol também favoreceu positivamente na extração de fenólicos. Em relação à cinética de extração, verificou-se que o aumento da concentração de compostos fenólicos e da capacidade antioxidante em relação ao tempo de extração variou de acordo com as condições de cada ensaio, sendo que para maioria dos ensaios o tempo ideal ficou entre 5 e 15 minutos.

\section{Conclusões}

Conclui-se que outros métodos de análise de capacidade antioxidante devem ser realizados para a confirmação dos resultados, como por exemplo o Orac (Oxygen Radical Absorbance Capacity).

\section{Agradecimentos}

Ao CNPq, pela bolsa concedida.

\footnotetext{
${ }^{1}$ SINGLETON, V. L.; ROSSI, J. A. Colorimetry of total phenolics with phosphomolybidicphosphotungstic acid reagents. American Journal of Enology and Viticulture, v. 16, p. 144-168, 1965.

${ }^{2}$ RUFINO, M. S. M et al. Metodologia Científica: Determinação da atividade antioxidante total em frutas pela captura do radical ABTS.+. Comunicado Téenico (Embrapa Agroindústria Tropical), 2007
} 